\title{
DA FRAGMENTAÇÃo dOS SABERES À ANIQUILAÇÃo DOS DIZERES, A ERUDIÇÃo SEM NOME
}

Rogerio Ribeiro Tostes ${ }^{48}$

Estar dentro e fora de uma posição ao mesmo tempo - ocupar um território e ficar vagando ceticamente pela fronteira-é, com freqüência, de onde brotam as idéias mais intensamente criativas. É um lugar cheio de recursos para se estar, mesmo que nem sempre seja isento de dores.

Terry Eagleton. Depois da Teoria.

Resumo: O desassossego intermitente das ciências sociais sobre seus objetos de estudo parece ser, contemporaneamente, um mal causado pelas indefinições de seus postos teóricos antes consagrados. A institucionalização dos espaços de pesquisa e divisão científicas atravessa um ponto de divergência segundo a convocação de novas diretrizes epistemológicas, debaixo da qual a interdisciplinaridade dos recursos intelectuais é reclamada diariamente. Para este trabalho, portanto, não se omite um certo viés ensaístico, no qual se conjuga, à ligeira análise dos pontos de concentração da teoria cultural, uma direção próxima sobre a transformação dos destinos das ciências sociais e de suas prioridades metodológicas mediante o ofício do intelectual e intérprete. A reflexão neste instante insere-se, então, aos limites negociados de uma crítica da teoria e das ciências sociais em transformação.

Palavras-chave: história intelectual; estudos culturais; crítica das ciências sociais.

Partindo de uma primeira experiência com a historiografia medieval, e mesmo dotado de uma base por demais estreita sobre ela, não temos deixado de voltar sempre alguma atenção aos questionamentos afiambrados ao valor metodológico do fazer histórico e das ciências humanas como um todo. Neste momento, não é pouco comum que sejam dirigidas críticas específicas aos estudiosos medievalistas por seu recolhimento abstencionista sobre os mais recentes emblemas dos torneios epistemológicos travados em âmbito acadêmico. Estas críticas, que ultimamente têm conjurado um teor mais acusativo, atacam a impronúncia metodológica e a carência das práticas de descrição realizáveis a partir de suas fontes e de seus resultados mais significativos. Assim, além de uma desconfiança plantada sobre o seu isolamento teórico, toma corpo também a opinião de que sua omissão pouco contribui ao encontro de outras áreas da pesquisa histórica, estas que, por elas, são reputadas mais úteis e mais produtivas sobre esse tipo de reflexão historiográfica.

De nossa parte, procuraremos desmentir tal afastamento, assumindo sempre que possível os instrumentos e categorias trazidos por esse novo contexto intelectual não apenas em relação aos nossos objetos de estudo, mas também ao desenvolvimento atual sobre os limites constitutivos do 
fazer historiográfico. À semelhança dos demais ramos do conhecimento histórico, o medievalismo não se isentou dos cambiamentos promovidos por uma guinada hermenêutica do presente sobre a apreensão representativa do passado.

Fruto desses transportes, surge, principalmente no cenário norte-americano, a proposta de um novo medievalismo, o qual atenderá a um programa de renovações temáticas e epistemológicas a partir dos anos $1970^{49}$. Infelizmente, muito desse programa ainda não transcende o percurso alinhavado pelos pós-estruturalistas e pela voga da linguistic turn, tal como esta ficou conhecida sob a sistematização oferecida, dentre outros teóricos, por Richard Rorty (1992). Estimaríamos que com o advento desse medievalismo se pudesse ousar um pouco mais, e que ele tivesse meios de assumir uma crítica que fosse além dos problemas suscitados por linguagem e discurso - ainda que reconhecêlos seja igualmente importante - para transcender mais um pouco, ao ponto de confrontar os limites de seu alcance técnico metodológico. Para este primeiro apoio, no entanto, quer-se traçar uma forma de reflexão em tudo mais ampla e mais genuinamente heurística, abandonando por momento os problemas específicos da historiografia medieval para lidar com as convocações mais urgentes desse contexto intelectual, e isto mesmo por mais ubiqüitante que ele nos pareça ser até agora.

\section{Um vislumbre panorâmico: algumas digressões de método}

Nas últimas décadas do século XX, um espectro de demolição açambarcou a cena teórica a partir dos grandes centros intelectuais ocidentais. Uma generalização crítica prorrompeu contra toda forma de tradicionalismo teórico, enclausuramento ideológico e autoritarismo estético. Desde os bramidos do linguistic turn - que associava a construção social, histórica e cultural, como apreensão da linguagem a superar o elemento empírico nas práticas da descrição da realidade - até as recentes altercações promovidas pelos estudos culturais, instaurou-se um debate que confinou as ciências sociais a um jogo de auto-reproduções interminável. De parte dessas condições, a nossa proposta aqui é conciliar o diagnóstico e a reinterpretação semântica dessa crítica teórico-metodológica sobre a reflexão cultural vigente.

Sem querer propriamente repisar o freqüentado terreno das ponderações que relacionam esse mesmo debate, gostaríamos de acrescentar uma pontuação pessoal no envolvimento de suas tendências epistemológicas, às vezes ingênuas e disparatadas, de renovação cognitivo-instrumental da modernidade tardia. É este imenso relvado ideológico que, no presente, à falta de nomenclatura mais apropriada, se costuma invocar sob o título de pós-modernidade.

Em geral, quando se fala em pós-modernidade, tem-se presente a matriz de fundamento 
dialético erigida pela crítica cultural das últimas décadas; nomeadamente, a representada pela: (1) recente geração dos teóricos frankfurtianos, (2) pelos pós-estruturalistas franceses, seus naturais contendores, e (3) pelos militantes da voga do New Criticism, que de alguma forma parte dos dois postos anteriores para refletir a conjuntura cultural norte-americana. Assim, o debate aparece atrelado fundamentalmente à volta de dois grandes temas principais: o político-filosófico e o científicoepistemológico.

A partir deles, um conceito mais ou menos genérico de pós-modernidade invade os espaços especializados e públicos de conhecimento teórico, nos quais persiste uma deformidade elusiva sobre sua realidade programática e estrutural, resvalando num julgamento engessado que reduz suas prioridades à condição de mera desestabilização, irracionalidade e relativização das verdades consagradas pela tradição modernizadora. Em nome desta perspectiva, Terry Eagleton, intelectual marxista e consagrado teorizador da atual crítica cultural, sintetiza a pós-modernidade segundo esta inserção conceitual:

\begin{abstract}
"Pós-moderno" quer dizer, aproximadamente, o movimento de pensamento contemporâneo que rejeita totalidades, valores universais, grandes narrativas históricas, sólidos fundamentos para a existência humana e a possibilidade de conhecimento objetivo. O pós-modernismo é cético a respeito de verdade, unidade e progresso, opõe-se ao que vê como elitismo na cultura, tende ao relativismo cultural e celebra o pluralismo, a descontinuidade e a heterogeneidade. (EAGLETON, 2006, p. 27, nota 3)
\end{abstract}

Sua análise sobre o assunto é genericamente correta, mas não isenta de um certo partidarismo ideológico que a compromete. Naturalmente, ele irá combater as avaliações dos pós-estruturalistas franceses que iriam decretar a completa deserção das metanarrativas, e junto a elas, aniquilar o próprio valor histórico mantido pelo marxismo. A par disto Eagleton nos lembrará, junto de outros, que há um equívoco forte indiciado pelo pós-modernismo, que pressente na sucessão temporal histórica uma conotação semântica de construtivismo e de progresso: a pós-modernidade emergiria do ponto exato em que a modernidade terminaria, impondo uma cronologia que se procura manter a custa de negações e superações temporais, reproduzindo a errática fórmula gerada pela própria modernidade de uma seqüência histórica e metanarrativa que engendraria o fim da história. Nestes termos, sua fórmula libertadora acabaria por ressuscitar aquilo a que se propunha remover, transformando sua denúncia em uma nova e embaraçosa contradição.

De fato, para conter esse posicionamento, a designação de pós-moderno é inadequada, mas é justamente por conta dessa inadequação que ela remonta antes a um sintoma que a uma solução (LATOUR, 1994, p. 73). Essa talvez acabe por ser a principal causa de sua controvérsia e rejeição pela maioria dos teóricos vanguardistas, da filosofia estrutural à teoria da história, e apenas encartado pelos cientistas sociais inseridos no universo de uma corrente chamada de Crítica Cultural. Com isso, há que se observar o advento de duas "correntes interpretativas" sobre o fenômeno, antes de tudo epistemológico, da condição pós-moderna; primeiro, um partido fortalecido institucionalmente no interior da academia, que associa a ela toda sorte de negação e de aniquilamento, ao limite mesmo 
de sua suposta irracionalidade contra um apego desmesurado aos seus próprios instrumentos e a sua inteligibilidade metodológica.

Hoje, a questão não é mais detectar o eixo antinômico representado pelo pós, no qual sua popularização acabou por marcar um estreitamento terminológico de anti-modernidade residual, limitada a um "episódio (ainda que significativo) dentro de uma certa transformação da própria modernidade ocidental" (HUYSSEN, 2002, p. 20). Sua invocação perdeu no presente grande parte da antiga polêmica nas discussões sisudas entre os scholars dos altos meios acadêmicos, valendo apenas precariamente por sob os discursos mais intransigentes anti-modernistas dos que são avessos a qualquer sinal de normatização do conhecimento teórico.

O segundo movimento, fica pois por conta dos teóricos sociais, que em busca de uma posição eminentemente política, partem em direção do complexo movido pela interdisciplinaridade dos mecanismos de reflexão cultural, e que enxergam nesta guinada pós-moderna a ocasião libertadora da crítica, até alcançar, finalmente, a oportunidade de se reconduzir os preceitos ideológicos dá emancipação-e porque não dizer logo, de um sistema de idéias reposicionado para além das prioridades iluministas da razão instrumental, historicista e progressista. Na verdade, para seus defensores, a proposta pós-moderna tem aspirações mais profundas - ou pelo menos, alternativas. Defensáveis, por exemplo, no prosseguimento das primitivas teorias utópicas em vias de exaurimento, e na contralógica daquela gestada pelo capitalismo ocidental como realização triunfante de emancipação social e política (SANTOS, 2000).

Porém, a sua complexa existência tem a dever outras fontes, fornecendo elementos contrassertivos propagadores de uma crítica polissêmica. Assim, posteriormente, a discussão foi enriquecida por um novo elemento axiológico. Naturalmente, falamos do constructo reconhecido pelo nome de pós-colonialismo, cuja violenta desconstrução aporética acusa a tradição modernizadora ocidental de opressão e absolutismo racionalistas. Ela é, antes de tudo, uma resposta ao paradigma eurocentrista de conformação das verdades fundantes, ao unilateralismo de uma cultura totalizante que se arroga a ser porta-voz de um único Ocidente, egresso do imperialismo e da univalência cultural dos países do norte. Sua proposta se enfileira ao lado de outras digressões críticas, tais como as vertentes que rechaçam o sexismo, oracismo e a influência de predominâncias culturais hierarquizantes; pretendendo, para além da imitação subserviente dos expedientes imperiais, produzir um discurso próprio, autêntico, haurido em sua contínua re-inscrição de valores e sistemas simbológicos em oposição ao fundamentalismo cultural. A particularização do presente, inferido de uma oportuna teoria de tradução, remonta à contingência de um discurso identitário, por si só transitório, de uma modalidade ética cultural e histórica.

Daqui outro substrato, vindo diretamente da teoria da história e dos teóricos da cultura, em que a oposição entre história e memória, entre "passados presentes" e "passados futuros" (HUYSSEN, 2000), e finalmente, entre a tradição de uma grande síntese histórica e a corrente designação das pequenas escalas oferecidas pela micro-história, produzindo um sentido particular às narrativas 
e à própria reformulação das subjetividades. 0 embate entre tempo histórico e tempo memorial decorre não só das naturezas dissonantes em suas relações com o passado, mas também nas reservas epistemológicas do primeiro sobre a "ingenuidade" de método do segundo. No entanto, a consciência mais assentada da memória quanto a sua própria razão discursiva lhe garante um espaço mais firme - e vale dizer, menos controvertido e difuso - em sua tarefa de reproduzir a experiência do passado, mais do que atualmente a história tem podido atingir. A persistência inglória de a história reproduzir totalidades temporais foi que lhe arremedou a sua marca substantivista até os dias de hoje, negando a impronunciabilidade da sua aspiração pelo rigor confiante de seu método.

Tal qual o lastro de suas propostas se diferem, o entrosamento constante de seus objetos não pode mais recrudescer. Sob este passo, a problematização da antiga querela resvala no entendimento que se pode ter dos conhecimentos do passado e dos conhecimentos sobre o passado. Tanto um quanto outro se submetem às contingências enganadoras do processo de linguagem, e de seu sucedâneo, o registro do discurso. Também, impulsionador desse novo facho teórico, os estudos sobre a memória devem muito ao estímulo oferecido pela fragmentação pós-modernista, "já que não é possivel sustentar uma Verdade, florescem em contrapartida verdades subjetivas que afirmam saber aquilo que, até três décadas atrás, se considerava oculto pela ideologia ou submerso em processos pouco acessíveis à simples introspecção" (SARLO, 2007, p. 39). A flexibilidade de discursos entre os postos intelectuais e os postos públicos, de onde o testemunho oral da comunidade anseia a sua equivalência para com o erudito, estabelece um primeiro conectivo, ainda estranho as suas órbitas, que ora pleiteia seu espaço na formulação do presente para até mesmo cooptar seu vigor ao futuro.

\section{Erudição e interdisciplinaridade}

Levantemos alguns pontos críticos. Primeiro, em "Conhecimento e Política", Roberto Mangabeira Unger defende que os sistemas de conhecimento são constituídos por complexos de uma tradição teórica dita clássica, pré-ordenadora de todas as ramificações especializadas. Em vista de sua unidade, o sistema clássico só pode ser passível de uma crítica total, e não meramente parcializada no interior de ciências especializadas - "Para efetuar esta crítica total teria que primeiro realizar o esforço de restaurar todo o sistema e trazê-lo à luz" (UNGER, 1978, p. 3). Desta forma, a teoria do conhecimento é um problema intimamente conexo ao da teoria política, vez que ela faz depender, através dos modos de solução de seus problemas a respeito da sociedade, também os problemas encontrados pela investigação do conhecimento. Assim, do estudo do conhecimento, ao entendimento da ação individual, as teorias do comportamento social e a psicologia das práticas públicas, tudo se mantêm preso a um intenso fio condutor responsável pela continuidade dos parâmetros desse sistema unificador de pensamento tradicional.

Neste caso, abandonando sua primeira perspectiva, "unificadora" das ciências como sistema a ser restaurado, projeto do qual sinceramente desconfiamos, retém-se o segundo eixo - se é que admiti-lo fora do primado do anterior não resulte em prejuízos lógicos, com a secção do conjunto - 
onde se relaciona o conhecimento científico ao conhecimento político sobre a produção de unidades auto-certificantes de valor teórico.

O segundo. Em um artigo apresentado em 2001, escrito a propósito de um colóquio de iniciativa da Associação Brasileira de Literatura Comparada (Abralic), o professor Andreas Huyssen, titular de Estudos Germânicos na Universidade de Columbia e reconhecido continuador dos frankfurtianos, declara que os estudos culturais no atual estágio de seu debate não estão aptos a fornecer um modelo adequado para se entender o fenômeno das culturas globalizantes. E isto, diz ele, fica por conta dos últimos engates teóricos que desenvolveram a tendência pós-modernista nos Estados Unidos - o que quer dizer que, neste caso, quando o seu espaço ideológico foi tomado pela anti-elitização cultural, ele acabou por ignorar completamente o emprego da divisão entre o popular e o erudito, eliminando com ela as ferramentas críticas acerca do sentido estético do próprio modernismo.

A relação entre erudito e popular aparece aqui, remete Huyssen, ao princípio dos debates esquerdistas declarados entre os anos de 1930, assumindo toda a sua "preocupação constante com questões de valor estético e percepção estética em relação à política, história e experiência" (2002, p. 23). O que essas referidas ferramentas permitem, afinal, vai muito além dos programas pósmoderno e pós-colonial para produzir uma síntese mais completa do entrosamento entre o estético e o político e no avivamento de um plano já em vias de esquecimento por essas últimas duas críticas culturais. De certa forma, e quase não há quem discorde disso, o pós-modernismo (cultural norte americano) descende diretamente do aniquilamento das fronteiras que delimitavam cultura erudita e cultura popular - em especial, a mass media norte-americana. Após o que, assumiu, perigosamente entusiasmado, os genes de uma vontade cultural pluralista capaz de assimilar todas as espécies de discursos - principalmente aqueles até então marginalizados - num acesso furioso de contracultura estrutural. No entanto, hoje a divisão entre os discursos culturais permanece, e os ataques sistemáticos do pós-modernismo acabaram não logrando superar a dicotomia do erudito e do popular.

A diversidade de saberes celebrada pela fragmentação epistemológica pós-moderna responde pela ascensão ideológica de uma forma inteiramente nova de percepção da realidade. É ela quem passa a assumir feições canônicas sobre o cenário acadêmico pela conformação de discursos "ecléticos" acerca do conhecimento científico em oposição ao saber teórico tradicional, ultra-especializado e elitista, denominado burguês pela crítica marxista dos anos 1960. Através deles, destaca-se a valorização cada vez mais veemente de divisas como humanidades e estudos culturais para reportar um número cresçente de aptidões intelectuais antes isoladas por disciplinas herméticas e concentradoras, passando então a assumir uma operacionalidade conjunta segundo a proposta teórica de um novo perfil de erudição. É de notar que estas são as condições reinantes no ambiente acadêmico americano, mas ainda que de fato pouco se transcenda dele, elas acabam congregando de alguma forma as posturas gerais exibidas pelas ciências humanas atualmente na paisagem mundial. Ainda, deve-se considerar um segundo eixo em questão: 
sofisticação crítica às demandas conjecturais da sociedade pós-industrial, pautam-se também sobre a própria impronunciabilidade dos chamados "jogos de linguagem" inseridos em cada disciplina do saber. É justamente aquilo que Lyotard denomina de incomensurabilidade das formas lingüisticas o que obstrui as possibilidades de interação entre as várias ciências modernas. Não há maneiras de se propor uma epistemologia geral, como muitos ainda insistem querer, e isto porque os diferentes tipos de discurso atualmente existentes não aceitariam formas reducionistas de sobreposição em nome de uma teoria primordial, chamada clássica, em condições de reunir todas as ramificações especializadas para uma proposição total da tradição do conhecimento. (TOSTES, 2008, p. 324)

Por isso, do mesmo modo que a superação das incomensurabilidades parece cada vez mais improvável, também o abandono das distâncias criadas entre o erudito e o popular vem se tornando um projeto inviável sob a prática dos estudos culturais. Naturalmente que, agora, tal separação deve ser levada em conta segundo critérios diferentes daqueles até então examinados por Walter Benjamin nos anos imediatos ao pós-guerra, uma vez que os mecanismos de reprodução técnica vistos naquele instante se multiplicaram a um fabuloso patamar de complexidade existencial. Qualquer crítica formulada depois deve levar em conta esses novos parâmetros.

Mas, retomando o mote esboçado na epigrafe, o que a separação entre o erudito e o popular tem diante da emergência de um novo aspecto para o intelectual do presente (e não pensemos exclusivamente no erudito)? Ou ainda, o que a relação com as formas de impronunciabilidade dos diferentes jogos lingüísticos pode dizer sobre a possibilidade de um novo papel epistemológico do operador crítico (seja ele proveniente de qualquer área de conhecimento, seja ele o próprio culturalista)?

O novo intelectual, submetido a essa dupla influência (erutido/popular), aparentemente contraditória, resvala em uma imperiosa necessidade de recomposição. $\mathrm{O}$ instrumental tomado pela dicotomia leva a pensar, por exemplo, que a formação e a natureza específicas do tipo de teórico do presente e sua tradição intelectual circundante acabam assumindo um perfil estilizado. Com isso, o intelectual contemporâneo, ao lidar com as disjunções entre os espaços do erudito e do popular, não só produz uma noção de crítica cultural própria, mas também, e principalmente, uma qualidade específica na sua maneira de ser diante do mundo. Reflexo disso está, diríamos, na própria polissemia de linguagens assegurada pela pós-modernidade como contragolpe revolucionário, ou na diversidade de saberes e na heterogeneidade discursiva sobre a construção da mentalidade de um indivíduo ocupado com o ofício teórico. Porém, um efeito interessante mas comumente negligenciado pelo ânimo da crítica ao pós-moderno, parte do condicionamento fornecido por ele próprio no estabelecimento de um perfil de intelectuais dotados das mesmas ferramentas metodológicas armadas em volta da multiplicidade de sentidos, linguagens e dialetos culturais. A multiplicidade de meios e a aceitação de uma composição interdisciplinar marcam um ponto de transformação considerado ruptural sobre o comportamento metodológico tradicional, inaugurado principalmente sob o levante dos estudos culturais nos anos 1950 .

Assim mesmo, não se trata, certamente, de celebrar'a ruptura como esperança salvífica 
das humanidades. Sua presença é útil quando entendida como reposição crítica de percepções analíticas, lembrando Stuart Hall ao dizer que o que mais "importa são as rupturas significativas - em que velhas correntes de pensamento são rompidas, velhas constelações deslocadas, e elementos novos e velhos são reagrupados ao redor de uma nova gama de premissas e temas" (2003, p. 123). Desde que o mundo perdeu toda uma geração de intelectuais do peso de Jean-Paul Sartre, Claude Lévi-Strauss, Roland Barthes, Michel Foucault, Wilhelm Reich, Theodor Adorno, Raymond Willians, Fredric Jameson e tantos mais, o alinhamento de novos intérpretes das ciências sociais lhes esteve mais ou menos submetido, mesmo quando se tratava de ampliar este espólio. De igual forma, a institucionalização do papel do operador teórico das disciplinas sociais também seguiu essa trilha. Dessa maneira, a perspectiva canônica sobre o que é conhecimento teórico (incluindo em seu bojo todos os desdobramentos possíveis a sua natureza instrumental) foi tudo o que restou no nobre interior do conceito de intelectual, lembrando um pouco o que já fora nos dias áureos de engajament político. O representante dos estudos culturais foi aquele que reuniu em si por algum tempo esses elementos, transitando sempre que reclamado por áreas distintas das ciências humanas para sintetizar uma locução que atendesse simultaneamente a legibilidade do senso-comum e ao reconhecimento teoricamente válido no campo da militância social.

Demarcando sua origem nas décadas de 1950-60, com direito a um ápice nos anos 1980, os estudos culturais não inspiram mais aquele poder abrasivo sobre as forças retóricas das humanidades, nem é tampouco o elemento de síntese das criatividades intelectuais tomada a reboque dos teóricos da tradicional esquerda política - cuja representação esteve, na verdade, quase sempre guardada pelos vários bastiões do marxismo. Além disso, o afastamento do teórico sobre a ágora, autêntico espaço de enfrentamento político, converteu sua atuação de condutor dos movimentos transformadores da sociedade, ativo portanto nos espaços de consensualismo público, para a de agente irrevogavelmente confinado por trás das seguras paredes da academia. No entanto, se Bourdieu (1984) estava certo ao avaliar a morte do intelectual engajado, o extinto maitre-à-penser que se despede do mundo com Sartre, modelo de exportação para revolucionários em todas as partes, representou o término de uma atuação na arena política (na qual seu julgamento era recebido com algum valor prático sobre a consciência das massas) então sua sobrevivência dependerá da própria habilidade em libertarse dos esquemas de reprodução institucionais que o afivelam a uma lógica obsedante de autoreferencialidade praticada no interior das atuais ciências sociais.

Atualmente, a experiência nos tem mostrado que as disciplinas sociais se desconhecem. 0 trânsito entre elas, quando provocado, dá-se muito amiúde e com superficialidade, o que não raro aparece repleto de falseamentos e incorreções que vão muito além de uma ofensa às questões técnicas que as particulariza em suas especialidades. Faltà mesmo a sensibilidade investigativa proporcionada pela reiteração prática, transformada em habilidade intelectual e perspectiva crítica especializada. Assim a diversidade de questionamentos entabulados pelos vários setores de um espaço intelectual institucionalizado - que por sua vez também será político, dotando esses questionamentos de um compartimento público - não será suficiente a trazer uma racionalização equivalente de respostas 
objetivas sobre eles. No limite, viceja o problema da interdisciplinaridade (acrescendo aquilo que a crítica bourdieuniana chamaria de a relação social constituída entre disciplinas e seus representantes) composto ao espaço público destinado ao intelectual após os trâmites com a interlocução midiática, da qual ele passou a depender.

Qualquer esforço para uma posição crítica neste instante deve ser instaurada mediante a condição de instabilidade, delicadamente fronteiriça, em que vive o articulador da teoria social. Assumindo seja o papel do antropólogo ou do historiador, do jurista ou do sociólogo, esse papel deve ser mantido com acuro sobre as intermitências das zonas de transferência e atualização, reconhecendo nele algo que Terry Eagleton, como epigrafamos atrás, deslindará como o campo "onde brotam as idéias mais intensamente criativas" (2005, p. 65). Eis a demarcação difusa em que pairam as questões de inter-relação e integração intelectiva, engendradas por posturas alternativas e recombinadas ao longo da experiência histórica processante. Se há um saldo positivo das últimas críticas que vieram devastar as convicções científicas tradicionais, esse valor terá de ser encontrado não no poder saneador dos fiascos metodológicos da linguagem objetivista da ciência, mas por ser criador do vácuo aberto para a reposição de certos postos e outras prioridades então minimizados até as últimas horas pelo império do conhecimento que devia contar. A crítica que constantemente sofre a pecha da futilidade por ter se tornado incapaz de solucionar aquilo que critica, deveria ao menos ser recebida como um momento de reflexão sobre os hábitos auto-certificantes, rotineiros, de um velho ofício acerca dos instrumentos e da condição das ciências do homem e da sociedade.

\section{Referências}

AURELL, Jaume. "El Nuevo Medievalismo y la Interpretación de los Textos Históricos" in: Hispania, vol. LXVI, num. 224, septiembre-diciembre. Madrid, 2006, pp. 809-832.

BOURDIEU, Pierre. Homo Academicus. Paris: Minuit, 1984.

BOURDIEU, Pierre. O Poder Simbólico. Trad. Fernando Tomaz. 7ạ edição. Rio de Janeiro: Bertrand Brasil, 2004.

FREEDMAN, Paul; SPIEGEL, Gabrielle M. "Medievalisms Old and New: The Rediscovery of Alterity in North American Medieval Studies" in: American Historical Review, 103, 1998, pp. 677-704.

FRANTZEN, Allen J. Speaking two Languages. Traditional Disciplines and Contemporany Theory in Medieval Studies. Albany, NY: SUNY Press, 1991.

EAGLETON, Terry. As ilusões do pós-modernismo. Trad. Elisabeth Barbosa. Rio de Janeiro: Jorge Zahar Ed., 1998.

EAGLETON, Terry. Depois da Teoria: um olhar sobre os Estudos Culturais e o pós-modernismo. Trad. 
Maria Lúcia de Oliveira. Rio de Janeiro: Civilização Brasileira, 2005.

HALL, Stuart. Da Diáspora: identidades e mediações culturais. Trad. Adelaine La Guardia Resende [et al]. Belo Horizonte: Ed. UFMG, 2003.

HUYSSEN, Andreas. Seduzidos pela memória: arquitetura, monumentos, mídia. Trad. Sérgio Alcides e seleção de Heloísa Buarque de Hollanda. 2ª edição. Rio de Janeiro: Aeroplano, 2000.

HUYSSEN, Andreas. "Literatura e Cultura no Contexto Global”in: MARQUES, Reinaldo; VILELA, Lúcia Helena (org.). Valores: arte, mercado, política. Belo Horizonte: Ed.UFMG/Abralic, 2002, pp. 15-35.

JAMESON, Fredric. A virada cultural: reflexões sobre o pós-moderno. Trad. Carolina Araújo. Rio de Janeiro: Civilização Brasileira, 2006.

LATOUR, Bruno. Jamais fomos modernos: ensaio de antropologia simétrica. Trad. Carlos Irineu da Costa. Rio de Janeiro: Ed. 34, 1994.

LYOTARD, Jean-François. La Condition Postmoderne. Rapport sur le savoir. Paris: Minuit, 1979.

RORTY, Richard M. The Linguistic Turn. Essays in philosophical method. Chicago: University Chicago Press, 1992.

SANTOS, Boaventura de Sousa. A crítica da razão indolente: contra o desperdício da experiência. Coleção "Para um novo senso comum", v. 1. São Paulo: Cortez, 2000.

SARLO, Beatriz. Tempo Passado: cultura da memória e guinada subjetiva. Trad. Rosa Freire d' Aguiar. São Paulo/Belo Horizonte: Companhia das Letras/UFMG, 2007.

SARLO, Beatriz. Tempo Presente: notas sobre a mudança de uma cultura. Trad. Luís Carlos Cabral. Rio de Janeiro: José Olympio Ed, 2005.

TOSTES, Rogerio R. "Por uma outra integração: modernidade e territorialidade cultural na América Latina”. In: MENEZES, Wagner (org.). Estudos de Direito Internacional. Anais do 6ํ Congresso Brasileiro de Direito Internacional, v. XIV. Curitiba: Juruá, 2008, pp. 319-327.

UNGER, Roberto Mangabeira. Conhecimento e Política. Trad. Edyla Mangabeira Unger. Rio de Janeiro: Forense, 1978. 